\title{
O comportamento culposo
}

\section{Motta Filho}

1. - Muito embóra a separação entre o delito doloso e o culposo não fosse precisa, nos primordios da vida juridica, ela se encontra bem fixada, quando o direito penal conquista a sua autonomia. Ao estuda-la no direito alemão, Mezger escreve: - "A historia nos ensina a compreender a formação paulatina desta zona do direito como fruto de uma lenta e cada vez mais imperiosa exigencia das grandes necessidades da vida juridica. Ha quasi quatrocentos anos que domina pacificamente, em nosso direito, ao lado do delito doloso, o delito culposo; e não existe a mais leve espetativa de que possa desaparecer (1). Na verdade, o codigo alemão de 1822 parece inspirar-se nos ensinamentos dos praticos italianos sobre a culpa como quasi delito. $\mathrm{E}$ estes não faziam mais que debater um assunto que a sociedade, em todos os tempos, oferecia aos juristas. Alimena pretende encontrar nas leis de Hammurabi entre os fatos intencionais e os praticados por negligencia, uma verdadeira distinção. Nas legislações hindú, hebraica, egipicia, helenica, cartaginesa, encontrar-se-iam referencias a respeito. Os textos romanos são multiplos e varios. O objetivismo inicial, a preocupação pelo "exitus", facilitava, evidentemente, a conceituação da culpa sem o elemento intencional. Tuozzı chega a afirmar que, com os fragmentos exparsos, poderiamos reconstruir uma teoria da culpa (2).

(1) MeZger ob. cit. 2.0 vol.

(2) M. Scoevola, frag. $31,9,2$. 
Os romanistas que procuraram focalisar essa teoria, encontraram como base da mesma o criterio da previsibilidade e o da previnibilidade (3). Na lei das XII Taboas, por exemplo, ha referencias ao homicidio involuntario e á distinção entre o incendio doloso e culposo (4).

Como o direito penal romano estava incluido no direito geral, encontramos, por sua vez, dificuldade para distinguir a culpa civil da culpa penal. LETo chega a escrever, neste sentido que "numa linguagem em tudo diferente daquela do direito civil, - o dolo (voluntas propositum, consulto agere) vem em contraposição ao "casus", que compreende a "negligentia", não havendo qualquer referencia á "culpa levis", em contraposição á "culpa lata" (5).

Apreciando os varios momentos da historia romana e o desenvolvimento da propria semantica latina, verificamos que a culpa, nos tempos anteriores á republica, estava incluida na culpabilidade geral. Destacou-se depois, dando origem ao delito, ao quasi delito e ás contravenções de policia e sendo considerada como "lata", "leve" e "levissima" A culpa lata ou "nimia negligentia" ou "culpa proxima" na qual "dolum repraesentat", passou, como excepção, do direito civil para o direito penal (6).

$2 .^{\circ}$ - A concepção objetiva acentúa-se nas leis barbaras, talvez devido ao caráter primitivo da sociedade germanica. Para ela, valia o fáto em si, o modo pelo qual o acontecimento se realisava. Assim, para a mentalidade dominante nas instituiçǒes juridicas e sociais, o homicidio voluntario era identico ao homicidio involuntario. Aliás, entre os gregos, era essa concepção que dominava, pois as leis de Dracon puniam não só os homens como animais e até objétos inanimados. Na época barbarica, os crimes cometidos pelos servos eram punidos quando causavam dano. Assim tambem eram os animais punidos. Citando varios exemplos do di-

(3) Gaio, frag. 9, 47, 9.

(4) Digesto, frag. $28,3,12$, etc.

(5) G. Leto - Il reato colposo, pg. 280, $1 .^{\circ}$ vol.

(6) Alimena - I limiti e i modificatori, etc., pag. 453, 1.0 vol. 
reito germanico, Giuseppe del Vecchro diz que, nesse direito, encontramos confundidas a responsabilidade real do proprietario e a responsabilidade diréta do animal (7).

Entretanto, tendo outra concepção do mundo, o direito canonico reage contra essa conceituação penal, estabelecendo que o homem como ser moral, é o unico sujeito ativo do crime. A maxima canonica "voluntas spectatur non exitus", torna-se regra de direito penal.

$O$ pensamento canonico, que domina e abraza a Idade Media, sofre varias influencias resultantes da libertação dos povos e da multiplicidade das correntes filosoficas. $O$ realismo romano porém, que se movimenta nessas influencias, facilita a aplicação do direito como regra de adatação social. De fáto, havia o pensamento de que o dolo era a expressão de uma vontade perversa, ocasionadora de um mal e, portanto, quem a possuisse, deveria ser punido: mas por. isso mesmo, em casos de imprudencia, de negligencia ou de impericia, que são atividades que não se referem á livre vontade do individuo, não havia motivo para haver punição. Por outro lado, mesmo assim, crimes culposos eram punidos, em face da concepção romana. Principalmente com a Escola de Bologna, onde o estudo do direito romano foi professado cuidadosamente, a distinção entre dolo e culpa, para os ef eitos penais, foi motivo de debates. Bonifacio de ViraLrNis procurou formular questões em torno de varios exemplos de culpa. E lembra a situação de um individuo que deseja matar um cachorro e mata um passante e que, por isso, não deve responder por homicidio - "sed actione injuriarum quia fuit in culpa" (8).

Em regra, os praticos procuram o verdadeiro significado da culpa e encontram dificuldades, chegando a fazer confusões, como o eminente Cujacio para quem a culpa latissima não é mais do que o dolo (9). Alberto de Gandino, Giu-

(7) G. Del Vecchio - Il soggetto attivo del reato, pg. 16.

(8) G. LETo - Il reato colposo, 1.० vol. pg. 11. pg. 282. 
lo Claro e Aretino fazem as distinções possiveis para a época.

A fecunda elaboração dos praticos italianos e alemães tiveram explicavel repercussão nas obras legislativas como nas constituições da Sicilia, promulgadas por Frederico II.

Nesse rumo encontramos uma noção legal mais precisa, nas interessantissimas constituições de Carlos V, em 1532. Elas já se referem "ao homicidio praticado sem intenção e contra a vontade do agente"

Pois, apesar do esforço dos juristas, as disputas em torno do assunto continuaram, concorrendo mais para isso, as novas formas de atividade social que o Renascimento e o modernismo of ereceram. A culpa ficava numa zona intermedia, imprecisa, constituindo, no dizer de LETo, um "quid medium" entre o crime doloso e o caso.

3..$^{\circ}$ - 0 movimento revolucionario do seculo XVIII apresentou-se com um carater acentuadamente subjetivo e libertario. A reação contra o perigo do arbitrio judiciario, contra o crime definido pela vontade do rei, obrigam novos estudos e a procura de novos horisontes. E é do protesto de BecCARIA, em 1764, que parte a nova orientação penal tendo em apreço os direitos individuais. Essa orientação encontra ambiente propicio para desenvolver-se. Ele depara o movimento industrial a creação da burguesia e a transformação da vida urbana (10). Quando PEREgrino Rossı investiga o problema da culpa penal (Traité du droit penal, cap. XXII), os exemplos sobre ela se multiplicavam. 0 eminente jurista procurava justificar a lei penal na necessidade social e nos principios morais. Para o seu espirito, que repelia a utilidade encarada como pretexto para a soluçấo de todos os problemas, a culpa aparecia como um dos mais graves problemas do direito penal. $O$ caso do empreiteiro que, sem ter em conta o regulamento de policia, ocasionava a morte de um operario ou de um tranzeúnte,

(10) Bertrand Russell - Liberdad y organización, pg. 75. 
que Rossi of erece como exemplo, serve para ele justificar a seguinte conclusão: "aquele que, deliberadamente, deixa de seguir as precauções prescritas para impedir um possivel sinistro, quer torna-lo possivel e a sua punição não deve ser apenas a titulo de culpa" (11).

A intensa curiosidade pelo mundo subjetivo, que foi um dos sinais carateristicos do seculo XVIII, domina inteiramente o direito penal e coloca o problema do crime culposo em situação mais singular ainda. Para Carmignani (Juris criminalis elementa) a culpa é explicada como um vicio de vontade (voluntatis habitus).

Em torno da vontade Carrara e Pessina procuram construir a doutrina da culpa penal. Para Carrara, é a omissão voluntaria das deligencias ao calcular as consequencias possiveis e previsiveis do proprio áto" (12). Nota-se, desde lógo, nessa definição, a mesma preocupação que já encontramos em Rossi, isto é, a voluntariedade fundamentando a culpa punivel. Quem conhece a obra de Carrara sabe que o grande mestre não podia afastar-se desse ponto de vista, porque, para ele, o magisterio penal, exercitado no Estado para impedir certas ações e aplicar castigos, decorre da lei suprema da ordem, imposta por Deus ao Universo. A lei juridica garante ao homem, internamente livre, o exercicio exterior de sua liberdade. Depois de esclarecer as duvidas de Almendingen e de outros que negam a imputabilidade na culpa, acentúa que esta é punivel porque envolve consequencias possiveis e previsiveis. E a essencia da culpa, diz ele, reside na possibilidade de prever, o que é bem distinto da previsão (13).

Pessina diz que a culpa se caraterisa pela ausencia de vontade e falta de previsão nas consequencias da ação. A culpa, diz ele, como bom subjetivista que é, - tem raizes na vontade humana.

(11) P. Rossi - Traitè de droit pénal, Bruxelles, 1850.

(12) Carrara - Programma.

(13) Pessina - Elementi di diritto penale, vol. 1, pg. 178. 
Segundo o modo de ver do consagrado penalista, aquele que não prevê as consequencias de suas ações e podia preve-las, dá a entender que não queria, de fáto, agir com atenção. (14).

Embóra subjetivista, Impallomeni tem uma atitude oposta, afirmando que o delito por culpa é essencialmente involutario. $O$ efeito lesivo não sendo desejado não permite haver culpa (15).

Para Berner, no delito culposo existe uma vontade viciosa. E GeYer, afirmando que todo homem tem o dever de ser atento, aceita a doutrina do vicio de vontade, o que tambem é aceito por Birk MEYER.

Merkel coloca-se no mesmo ponto de vista, dizendo que o delinquente culposo deixa sempre de evitar uma lesão a interesses protegidos pela lei.

Ortolan apega-se, tambem, á vontade para solucionar o problema do crime culposo (16), sustentando que, nesse crime, o áto que o constitúe foi desejado, mas lhe faltou a direção intencional para o evento danoso. Meister é mais seguro quando diz que a culpa é consequencia de um vicio de vontadie. Muitos outros escritores e não são poucos que, com este ou aquele ponto de vista, não abandonam, de modo algum criterio subjetivista. Outros vão além, na preocupação de uma justificativa de ordem moral, como VoN BurI e Kleischrod, transformando o crime culposo num verdadeiro caso de consciencia (17). Von Buri acha que o autor de um crime a titulo de culpa deve ser punido, porque, no nexo de causalidade que o produziu, ele intrometeu-se de módo a crear uma situação que interessa ao direito penal. Kleischrod, que vê no crime culposo um dos problemas mais dificeis do direito penal, sustenta que o autor de um áto qualificado crime é punido porque, tendo conscienciá
(14) Pessina - Obr. cit.
(15) Pessina - Obr. cit.
(16) Ortolan - Elements de droit pénal, § 1.0, cap. 2, 1.^ vol.
(17) Von BURI - Ueber Causalitat. 
da lei penal, sabe que deve observar sempre um certo gráo de deligencia para prevenir a violação do direito. Para Berolzheimer dá-se o crime culposo quando o agente omite aquilo que deveria fazer para que não se realizasse o efeito lesivo. Realiza-se, para ele, "a omisão de impedir um efeito proibido por lei" (18).

$4 .^{\circ}$ - Devido a influencia das ciencias naturais e principalmente devido ao desenvolvimento da antropologia, o conceito subjetivista muda de aspéto. São muitos os tratadistas que não se conformam com a explicação racionalista ou moral. A culpa não é um caso de consciencia e muito menos um vicio de vontade. E', para Almendingen e outros um "defectus intellectus", um erro de calculo, um vicio de inteligencia. Para o jurista alemão, a culpa fica inteiramente descolocada como materia penal, porque "a responsabilidade penal exige ação dolosa, ao passo que a culpa não revela forma alguma de criminalidade".

Nessa curiosa procura, as discussões aumentam, contradizem-se os julgados e tem-se, deante dos olhos, aquela "zona cinzenta" de que fala Grurati, na qual não se distingue o áto intencional do áto sem intenção, dando razão para que Prins afirme que "a terminologia juridica dos delitos involuntarios, a titulo de culpa, é inexáta. O legislador não pune e não pode punir senão as consequencias de um áto voluntario e si o áto inicial não é voluntario, o autor não pode ser responsavel por suas consequencias" (19).

Baldadas as objeções nesse sentido, porque o crime, a titulo de culpa, seja consequencia de um vicio de vontade, seja de um vicio de inteligencia, previsivel ou previnivel, áto consciente ou involuntario, reclama, pela sua repercussão social, uma medida penal.

$\mathrm{E}$ como hoje vemo-lo mais do que nunca na ordem do dia, dominando quasi que inteiramente o tragico quotidiano

(18) Berolzheimer - Filosofia del diritto trad.

(19) Prins - Sciénce pénale et droit positif, pag. 182. 
das cidades e dos centros populosos e como a imprecisão dos julgados evidencía sempre, a respeito, materia controvertida, dando motivo a injustiças, sente-se a necessidade de precisar as bases fundamentais firmes da punibilidade dos delitos a titulo de culpa.

5. - Quando um individuo é lezado, seja em sua pessoa, seja em seus bens, não ha poder, diz Mataja, que possa impedir que esse acidente se produza e que a vítima fique, mais ou menos em condições desfavoraveis. Se um raio destróe uma casa, acrescenta Haller, o seu proprietario não tem a quem recriminar. Quando um homem é que põe fogo na propriedade alheia, o proprietario reagirá de uma dupla maneira, procurando, por um lado, punir o culpado, conforme o gráo de civilisação a que se chegou, e por outro lado, reconstruir a casa incendiada com o auxilio do mesmo culpado (20).

A punição dá-se porém, porque mesmo que o áto não seja integralmente intencional, além de uma vítima, ha uma verdadeira ameaça á tranquilidade da paz comum. Mas, os delitos culposos são em regra, variados e complexos. A responsabilidade esconde-se, muitas vezes, numa serie de ações e de omissões (21). A autoridade julgadora tem, deante de si, leis do Estado, regulamentos de policia, oficinas e fabricas, organisações coletivas, variedades de emprezas de transportes, pericias, mal maior, consentimento do of endido, tudo isso se entrelaçando, complicadamente com o crime a titulo de culpa. E' de grande interesse pratico portanto esclarecer-se o caminho da justiça quando vae de encontro a um acusado por impericia, imprudencia ou violador de disposições regulamentares. Por falta de uma definição precisa vemos, não raro, a pratica de verdadeiros absurdos. A procura tateante de responsabilidades enfraquéce a noção do julgamento. Porque a imprecisão não

(20) M. Haller - Essai sur l'influence du fait et de la faute de la victime sur son droit à réparation, Paris, 1926.

(21) A. Kohlen - Deutsches Strafrecht, pg. 239. 
atinge tão só o crime a titulo de culpa, como tambem, muita vez, alcança o crime a titulo de dolo. A's vezes, em casos tipicos de "aberratio ictus", em que ha dolo e culpa ao mesmo tempo, vemos surgir no áto do agente, quer intencional ou não, a mesma personalidade agressiva e perigosa. Temos exemplo, num julgado do Tribunal de Relações de Minas Gerais para não citarmos outro: - 0 réo, com alguns companheiros, preparou uma emboscada para matar um individuo e quando este passava pelo local em que era esperado, foi alvejado por armas de fogo, morrendo por isso. Acontece porém que a vítima estava no momento acompanhada e quem a acompanhava recebeu tambem um tiro. Em tal hipotese, a jurisprudencia do Tribunal determina seja o delinquente considerado autor de um crime doloso, o que pretendia, de fáto, executar e autor de um crime fóra de seu proposito doloso. No caso, em apreço, de acordo com esse criterio, o réo praticou um crime de homicidio e deve ser punido pelo art. $294 \S 10^{\circ}$ das Consolidações e um crime de ferimento culposo, punido pelo art. 306 (22).

Assim, para a pratica de um áto qualificado crime, com a circunstancia agravante da emboscada, o criminoso deixa de apreciar a probabilidade de vitimar pessoas extranhas a seus designios. Ele que calculou, que planeou, que tudo fez, com previsão e cuidado, para que não falhasse o áto criminoso, - não previu, não calculou a extensão desse áto e suas consequencias.

No entanto, quem estuda a pluralidade de lesões provocada pela unidade de ação no direito penal, sabe que o assunto preocupa demasiadamente os juristas, chegando Pessina, Von Buri, Wachter, Kostlin, Walter, Litszt, Carrara, Nicolini, Garraud e outros a sustentar que se trata de um unico crime doloso, sustentação aceita pela jurisprudencia, francesa, hungara e austriaca. Concordando, por sua

(22) Revista de Criminologia, 8-1928, pg. 418, S. Paulo. 
vês, com esse ponto de vista, ensina o douto Alimena: "Tambem acreditamos que se trata de um só delito, um delito doloso. A razão é evidente. De fato, como diz Pessina, o homicidio consumado por "aberratio ictus", não pode dar motivo para que se diga "o ef eito não querido de um fato licito; é um efeito de um esforço criminoso, efeito de um golpe vibrado com intenção de matar alguem. Efetivamente, o objéto do homicidio ou da lezão é o homem e não 'Tizio ou Caio. Se se desejava pois matar ou ferir um homem e um homem foi morto ou ferido, eis o essencial para o ferimento ou o homicidio: o ser morto ou ferido Tizio ao em vez de Caio é um erro meramente acidental que não destróe o que é essencial para o homicidio ou para a lesão" (23).

Por isso tudo, vemos, na complexidade do áto punivel focalisado agóra, dois aspétos diversos unificados por um mesmo gesto designativo de um individuo perigoso, refletido para o mal, irrefletido em na mesma circunstancia. E se examinarmos o caso, em sua feição psicologica vemos, como que assinalando as dificuldades do problema, que o criminoso justamente para prever os resultados do crime, para realizar aquilo que sua vontade queria, esqueceu-se do mais. Aliás, um homem que concentra num determinado fóco, todo o interesse de sua vida, como que esse se envolveu numa atitude criminosa, não pode ser olhado como um imprevidente.

Ao mostrarmos este exemplo (e poderiamos mostrar ainda outros), é nosso intuito realçar que o problema da culpa, of erecendo varios aspetos, todos eles necessarios para defini-lo, tem a mesma raiz e o mesmo fundamento que o crime doloso.

6. - As doutrinas sobre a cúlpa penal deram sempre, principalmente na Alemanha e na Italia, motivo para os mais interessantes debates que visam, em sua grande maio-

(23) B. Alimena - Enciclopedia Pessina, vol. V, pg. 553. 
ria, a fixação da linha diretôra da justiça penal num caminho cheio de atalhos e dificuldades.

Quando se pune um homem por áto qualificado como culposo, a punição, longe de ser inesplicavel e de atuar numa zona cinzenta e inespressiva, tem suas raizes inteiramente confundidas com aquelas que justificam a punição de um crime doloso. Nem seria possivel pretendermos separar a doutrina da culpa penal do corpo doutrinario da função de punir.

Exigindo medidas repressivas, pelas consequencias que dela resultam, a culpa só pode ser conceituada dentro da teoria do direito, ou como culpa civil ou como culpa penal. Puglia coloca muito bem o problema em seus verdadeiros limites, quando diz: - "existem ações individuais, lesivas de direito, de natureza tão grave que perturbam profundamente a ordem social de tal módo que a simples satisfação do dano causado ou a méra reitegração do direito do ofendido ou do prejudicado pela ação malefica, não bastam para restabelecer a ordem, para tranquilisar a consciencia dos associados sobre a garantia de seus direitos, porque o temor das provaveis repetições daquelas ações perigosas, lança o alarme no animo de todos"

"Sente-se, em tais casos, a necessidade do emprego de remedios juridicos graves, com um duplo fim de tutelar os associados, não só contra os ataques ulteriores do autor do dano ou da of ensa, mas tambem contra as provaveis violações juridicas da parte daqueles que pudessem imita-los" (24).

Assim, não raro, uma ação humana, muito embóra não intencional, lésa o direito de tal modo e perturba tanto a ordem social, que exige ou provóca remedios juridicos extremos.

A sociedade humana exige de seus consociados um determinado comportamento. R. Maunier, ao qualificar os

(24) Puglia - Prolegomenos ao estudo do direito repressivo, pg. 45. 
fátos sociais, fala na uniformidade do pensamento e na conformidade na conduta. (25) Bouglés, tratando do mesmo problema, assinala a formação "de um sistêma de instituições necessarias para que os individuos possam viver em conjunto" (26). Passando pelas teorias sociais, que vão de Emile Durkheim a Simmel verificamos que, em todos os estagios sociais, ha uma uniformidade geral de compartamento, resultante da acomodação do individuo ao todo social. O contratualismo de Rousseau, a lei dos três estados de Comte, as leis de imitação de TARde ou o equilibrio instavel de SPENcER são expressões da maneira social da humanidade. Por isso Ricardo Oxamend, ao expor a sua interessante doutrina sobre a genese do delito, diz: "A causa do vicio, da miseria, do delito, das guerras, das revoluções descança na maior disparidade entre a evolução do espirito individual e o espirito social do homem no seio das sociedades humanas, em cada momento historico; daí a diferença que se observa no aumento ou diminuição dos males sociais e em particular do delito, nas varias edades da historia, no seio de uma mesma sociedade ou entre sociedades distintas, entre varias épocas de uma mesma sociedade ou entre sociedades diferentes, entre as diferentes épocas de uma mesma sociedade e entre os diferentes individuos de uma mesma sociedade ou ainda entre as diferentes socidades entre si (27).

O direito, que é technica da adatação social, atúa para a conservação desse "modus vivendi" e, inumeras vezes, socorre-se de medidas repressivas.

Por isso, matar alguem é crime e é criminoso aquele tentar dirétamente e por fátos destruir a integridade nacional ou opor-se, com violencia ou ameaças, a execução de ordem legal emanada de autoridade competente, que of ender á moral publica ou aos bons costumes. E para garantir,

(25) R. Maunier - Définition et division des faits sociaux.

(26) Bouglés - Qu'est-ce que la sociologie?

(27) Ricardo Oximend - El delito, pg. 16. 
o mais possivel, a linha do comportamento social do individuo, a lei penal considera como criminoso, aquele que expõe a perigo de morte ou de grave iminente dano á sáude oll corpo, ou abandonar e deixar em desamparo menor inferior a sete anos, fatigar fisica e inteletualmente por excesso de trabalho menor de 18 anos, etc. $O$ gatuno que furta, o falsificador que falsifica, o funcionario que prevarica são individuos que despresaram o sentido da vida em comum e que por isso são chamados á ordem por meio de uma medida sensivel, que sé denomina pena.

0 mesmo se dá com o individuo que age criminosamente em consequencia da falta de atenção, de cuidado ou de pericia. Haus escreve que ha culpa quando o individuo, sem querer violar a lei, omite os cuidados que devia empregar (28). Ele quer dizer com isso que o individuo não se comportou como era de seu dever, foi imprudente ou inépto, imprevidente ou imperito, descuidado ou desatento. Para Berner o erro, para justificar a punição a titulo de culpa, deve ser um erro evitavel, o erro que resultou da falta de atenção que, comumente se emprega na vida ordinaria (29). Assim Romagnosi, por sua vez, focalisa a atitude humana inconviniente quando diz que o crime culposo se origina da auzencia de uma certa cautéla encontravel comumente em todos os homens (30).

A mesma preocupação confessa te-la Stoppato para quem o homem, tendo o dever juridico de agir, com meios que correspondam ao fim social, não agiu na escala desse dever. Para o mestre italiano não pode ser bom cidadão, o que não cuida das consequencias do proprio áto. E acrescenta ainda que, aquele que vive em sociedade não só não deve querer a violação do direito de outrem, como tambem,

(28) Haus - Droit pénal Belge, pg. 185.

(29) BERNER - Lehrbuch des deutschen Strafrechtes.

(30) Romagnosi - Genesi del diritto penale, parte $3 .^{\circ}, \S 96$. 
mesmo agindo para um fim licito, deve usar de meios normais á idéa do direito (31).

SABATrisi, embóra generalisando demasiadamente o conceito da culpa, compreende-o em sua essencia, quando afirma que ela resulta de um estado de inercia psiquica (32).

Von LIszT, em poucas linhas, diz o valôr do delito culposo como comportamento anti-social, quando o definiu como "o não conhecimento contrario ao dever, da importancia da ação ou da omissão como causa" (33).

Brusa refere-se aos efeitos danósos da vontade, quando trata do crime culposo. Para ele tambem ha um modo de agir contrario ao dever, porquanto a culpa é a "omissão voluntaria da deligencia necessaria para prever e prevenir um evento penalmente anti juridico, possivel, previsivel e prevenivel" (34). Feuerbach, citado por Kleinschrod, diz que nesse crime ha uma violação de direito, porque, pelo contrato social, o cidadão deve ser deligente. E' o que encontramos, por sua vez, em LANzA e de maneira mais acentuada ainda em Impallomeni (35).

Alimena, que se deixa envolver pelas conquistas sociologicas, diz que "a teoria que, melhormente explica os crimes culposos, é a da condição psicologica e, portanto, do comportamento (36).

Angrolini, em sua teoria fisio-psicologica assinala a imprevidencia que caraterisa o responsavel, lembrando que Ferri já a encontrava no criminoso nato (37).

ManzinI, cuja influencia nos rumos atuais do direito penal italiano é indiscutivel, salienta que o crime culposo

(31) Stopatro - Evento punibile, pg. 206 e segs.

(32) Sabattini - Principi, II, n.o 162.

(33) Liszt - Tratado, pg. 290 e segs., 1.0 vol.

(34) Brusa - Saggio di una dottrina generale sul reato, pg101.

(35) Impallomeni - Codice Penale Italiano illustrato.

(36) Alimena - Ob. cit., 1.0 vol., pg. 448.

(37) Angrolini - Dei delitti colposi, pg. 65-66. 
é resultante de "uma conduta voluntaria genericamente ou especificamente contraria á policia ou á disciplina (38).

7. - Ha, portanto, na culpa penal, um ponto acertado e indiscutivel: - ela representa uma conduta anti-juridica, o que vale dizer, uma conduta que não está conforme com a conduta geral e que, por isso mesmo, desquilibra o sentido da garantia social. As ações e omissões cometidas com intenção criminosa são punidas, como tambem o são aquelas que resultarem por negligencia, imprudencia ou impericia. Ambas as condutas ameaçam a sociedade e ambas exigem a intervenção energica do direito por intermedio da pena. LETo acentúa, por isso, que deixar impune o crime culposo, equivale a tornar impossivel a associação civil. E lembra Carrara, quando dizia que o cidadão tem o direito de defender-se dos acederados como tambem dos patétas (39).

E' obrigação do Estado efetuar, pelo direito, a indispensavel acomodação social. A sua existencia prende-se a essa necessidade de ordenar os interesses da comunidade. Ele cria um sistêma de obediencias e comandos, de deveres e obrigações e age sempre com maior ou menor intensidade na defeza do bem comum. Pune-se o crime, culposo ou doloso, em nome do interesse geral que está ameaçado não só por esta ou aquela vontade insubmissa e arbitraria, mas por aquele comportamento que provoca um fato danoso, objetivo e certo. Um automovel que caminha, com excessiva velocidade, contra disposição regulamentar, só pode acarretar uma situação danosa ou perigosa para a sociedade. Essa situação não é criada pelo veiculo, ou por uma condição criada pela propria natureza das coisas. Ela resultou de uma interferencia humana, de uma forma humana de proceder contraria aos interesses sociais. $\mathrm{O}$ condutor desatento,

(38) MANZINI - La condotta volontaria. che ha causato l'evento dannoso, è contraria alla polizia o alla discinlina: - cenericamente, cioè, nelle ipotesi di negligenza o imperizia professionale; specificamente, nei casi di inosservanza di leggi, regolamenti, ordini 0 discipline. Instituzioni, pg. 85, 1935.

(39) Leto - ob. cit. pg. 140. 
o operador afoubado, o lavrador imprevidente, - todos eles agem e provocam uma situação perigosa e danosa e precisam ser contidos. Quando os navios transportam numerosas cargas humanas e valôres incalculaveis, quando as estradas de ferro assumem as mesmas responsabilidades; quando as fabricas trabalham com milhares e milhares de operarios; quando ha colegios com milhares de creanças e hospitais com centenas de doentes, - o direito precisa reafirmar a responsabilidade social do homem para evitar a consciencia da insegurança com a qual se torna impossivel a vida de uma coletividade. "O motorista, diz uma decisão da Côrte de Apelação, de 1908, - que dirige o bonde elétrico, tem por dever durante o trajéto de inspecionar a linha que percorre, sendo negligente e imprudente se não pára o veiculo imediatamente, desde que, veja um vulto qualquer sobre os trilhos. Se de sua desatenção resultar qualquer acidente, deve ser responsabilisado criminalmente"

"O fáto de alguem, diz um acordam do Tribunal de Relação de Minas Gerais, - sem habilitação, sem os conhecimentos precisos, tomar a direção de um automovel, já denuncia manifesta imprudencia de sua parte, - qualquer evento danoso resultante desse gesto deve ser tido como culposo"

E' evidente que esse comportamento não basta para definir o crime culposo, mas é ele que justifica perfeitamente a sua punibilidade. 